Fixed Point Theory, 19(2018), No. 2, 449-452

DOI: $10.24193 /$ fpt-ro.2018.2.35

http://www.math.ubbcluj.ro/ nodeacj/sfptcj.html

\title{
BEST PROXIMITY POINT THEOREMS FOR NON-SELF PROXIMAL REICH TYPE CONTRACTIONS IN COMPLETE METRIC SPACES
}

\author{
CLEMENT BOATENG AMPADU
}

31 Carrolton Road, Boston, MA, 02132-6303

E-mail: drampadu@hotmail.com

\begin{abstract}
Recall from [2], that a mapping $T: X \mapsto X$ is called a Reich mapping if it satisfies for all $x, y \in X, d(T x, T y) \leq a d(x, T x)+b d(y, T y)+c d(x, y)$, where a,b,c are nonnegative and satisfy $a+b+c<1$. Alternatively, one could define a Reich mapping as follows: $T: X \mapsto X$ is called a Reich mapping if there exists a nonnegative constant $k$ with $k<\frac{1}{3}$ such that $d(T x, T y) \leq$ $k[d(x, T x)+d(y, T y)+d(x, y)]$. In the present paper, we address the following: How do we characterize Theorem 3 [2], when $T$ is a non-self map? We show such a characterization is given by Theorem 3.1 or Corollary 3.2 in this paper.

Key Words and Phrases: Fixed point, best proximity point, contraction, proximal contraction, proximal cyclic contraction, Reich contraction.

2010 Mathematics Subject Classification: 47H10.

\section{REFERENCES}

[1] G.E. Hardy, T.D. Rogers, A generalization of a Fixed Point Theorem of Reich, Canadian Math. Bull., 16(1973), no. 2, 201-206.

[2] S. Reich, Some Remarks Concerning Contraction Mappings, Canadian Math. Bull., 14(1971), no. $1,121-124$.
\end{abstract}

Received: March 10, 2016; Accepted: August 10, 2016. 